\title{
Erratum zu: CSR und Inklusion
}

\author{
Andrea Sihn-Weber
}

\section{Erratum zu:}

\section{A. Sihn-Weber (Hrsg.), CSR und Inklusion, Management-Reihe Corporate Social Responsibility, https://doi.org/10.1007/978-3-662-62114-1}

Durch ein Versehen in der Produktion wurden irrtümlich viele Korrekturhinweise in den Text aufgenommen. Diese Texte wurden gelöscht.

Außerdem wurden die Abbildungen 1-3 im Kapitel MTOP | Inklusion aus verschiedenen Perspektiven ausgetauscht. 